\title{
Luces y sombras de dos paradigmas del americanismo español en la renovación del diálogo hispanoamericano (1909-1912) ${ }^{1}$
}

\author{
Gabriela Dalla Corte \\ y Gustavo H. Prado \\ Universitat de Barcelona \\ y Universidade de Santiago Compostela
}

Entre 1909 y 1911, el hispanoamericanismo español experimentó una renovación impulsada por iniciativas de la Universidad de Oviedo y la Casa de América de Barcelona. Ambas entidades, lideradas por Rafael Altamira y Rafael Vehils, lograron conformar dos paradigmas alternativos para la acción americanista. El primero definió una pauta de intervención fundamentalmente intelectual liderada por las universidades; el segundo, un modelo de intervención prioritariamente económico, ejecutado por asociaciones. Ambos paradigmas mostraron su carácter innovador al brindar propuestas concretas sobre casi todos los aspectos de la acción americanista y al proponer fórmulas que equilibren los intereses regionales y estatales.

Palabras clave: Americanismo, Universidad de Oviedo, Casa de América de Barcelona, Rafael Altamira, Rafael Vehils, s. XX.

Between 1909 and 1911, the Spanish Americanist movement was renewed by the initiative of the University of Oviedo and the Casa de América de Barcelona. Both institutions, respectively headed by Rafael Altamira and Rafael Vehils, were able to define two alternative paradigms to the Americanist action: the fist one defining a pattern of intellectual intervention led by the universities and the second one a way of economic intervention commanded by some associations. Both paradigms showed their innovative character by launching concrete proposals about all the aspects of Americanist action and proposing ways of balance between regional and state interests.

KeYwords: Americanism, Casa de América de Barcelona, University of Oviedo, Rafael Altamira, Rafael Vehils, s. XX.

El americanismo, como doctrina y como movimiento asociativo, ${ }^{2}$ logró abrirse paso en el mundo de las ideas y en la opinión pública españo-

1 Agradecemos los valiosos comentarios de Pilar Cagiao, directora del proyecto de investigación subvencionado por la Fundación Carolina, "El americanismo en España, 1898-1936: instituciones culturales y proyectos educativos", a Salvador Bernabéu Albert y a Eduardo Rey Tristán.

2 En relación con el concepto "americanismo asociativo" y al importante papel de las asociaciones como "agentes operativos" del hispanoamericanismo, seguimos a Sepúlveda Muñoz, Isidro: Comunidad Cultural e Hispano-Americanismo, 1885-1936, UNED, Madrid, 1994. 
las en la particular coyuntura comprendida entre los fastos del Cuarto Centenario del descubrimiento ${ }^{3}$ y el Desastre de $1898^{4}$. En aquellos años, pese a la activa colaboración de políticos, intelectuales y hombres de negocios de distintos orígenes, el movimiento americanista fue liderado por la Unión Iberoamericana (UIA) de Madrid, por mucho tiempo única asociación capaz de atraer el interés del Estado y de solventar grandes encuentros de confraternización internacional como el Congreso Hispanoamericano de 1900. La UIA inspiró buena parte de la "política de gestos" hacia las naciones hispanas y la organización de grandes eventos al calor de las propicias efemérides que se sucedieron durante aquellos años. Este americanismo, que pronto se constituyó en interlocutor privilegiado del movimiento ante el Estado y la clase política, articuló un modelo de intervención diplomática que aspiraba a auxiliar técnicamente las relaciones políticas y económicas entre el gobierno y las repúblicas latinoamericanas.

No obstante, al tiempo que afloraba en España un estado de opinión hispanoamericanista, el americanismo español fue haciéndose cada vez más complejo y diverso. Así, no debe extrañar que, a medida que se hacían visibles ciertas tensiones, algunas relacionadas con la captación o distribución de los siempre escasos recursos públicos o privados, las exhortaciones a la unidad de la acción americanista constituyeron un tópico de las diferentes asociaciones, que veían en aquella unidad un requisito para poder ofrecer un proyecto uniforme que, además de satisfacer las expectativas de sus diferentes exponentes, pudiese interesar al Estado.

En ese contexto y hacia el final de la primera década del siglo XX, se idearon dos estrategias alternativas de intervención americanista: la catalana y la asturiana. Los americanismos impulsados desde Barcelona y desde Oviedo se esforzaron por ofrecer diferentes soluciones institucionales y asociativas que, si bien no agotaron las diferentes expresiones del americanismo español, representaron dos paradigmas útiles para comprender mejor las opciones abiertas en el impulso renovador del diálogo con América latina. Los paradigmas, muy diferentes entre sí, resultaban innovadores ya que ambos definían un programa integral con propuestas concretas sobre todos

3 Véase en particular, Bernabéu Albert, Salvador: 1892, el IV centenario del descubrimiento de América en España: coyuntura y conmemoraciones, CSIC, Madrid, 1987.

4 Véase la obra de Maluquer de Motes, Jordi: España en la crisis de 1898, De la Gran Depresión a la modernización económica del siglo XX, Península, Barcelona, 1999, en la que el autor se refiere a la importancia de los gestos "patrióticos", consistentes en colectas y subvenciones, implementados desde el continente americano para ayudar a la monarquía española contra los Estados Unidos. 
los aspectos de la acción americanista: diplomáticos, legales, intelectuales, culturales, ideológicos, comerciales, productivos, impositivos, inmigratorios, postales, mediáticos. Además, proponían fórmulas alternativas para garantizar el equilibrio entre los intereses regionales y estatales: unos defendían principios de pluralidad, diversidad y autonomía; y otros sostenían el ideal de unidad. La cristalización de ambos paradigmas en el trienio 19091911 evidenció que, pese a la virtual unanimidad existente respecto de los grandes objetivos y más allá de las lógicas diferencias que pudieran existir alrededor de cuestiones puntuales, el ya heterogéneo movimiento americanista estaba atravesado por tensiones estructurales que se explican en parte por la diversidad de fines, ideologías y sensibilidades que albergaba. Así, las propuestas lanzadas desde Oviedo y Barcelona dan cuenta de que el movimiento no contaba con un diagnóstico común acerca de la realidad presente y futura de las relaciones hispanoamericanas ni disponía, por ende, de un único modelo consensuado para guiar sus intervenciones.

El estudio de los controvertidos hechos acaecidos tras el exitoso viaje americanista de la Universidad de Oviedo — protagonizado por Rafael Altamira-, mientras la Casa de América de Barcelona (CdAB) procuraba federar a las asociaciones americanistas del reino, muestra que, detrás de la colaboración inicial y de la manifiesta voluntad de mantener unido al americanismo, latía una considerable disparidad de intereses y proyectos entre los diversos grupos. De más está decir que la evolución del movimiento americanista fue, en el largo plazo, compleja y sinuosa. Si en los primeros tiempos las tensiones no se hicieron demasiado evidentes, a medida que transcurría la primera y segunda década del siglo XX fueron aflorando diferencias y en ocasiones se recurrió al gobierno en busca de legitimación y financiamiento. Por lo tanto, las tensiones tendían a resolverse a través del recurso al arbitrio estatal y a la transferencia de determinadas iniciativas del programa americanista a la esfera de la administración pública. El creciente interés de los sucesivos gobiernos españoles permitiría proyectar ciertos aspectos del americanismo al rango de política de Estado y abriría nuevos horizontes para sus referentes pero, en perspectiva, terminaría acotando sustancialmente el pluralismo inicial, condicionando la expansión de sus expresiones regionales y preparando el terreno para su casi completa absorción en los años ' 40 y ' 50.

Teniendo en cuenta la coyuntura de los años ' 10 —-donde se observa la tendencia a la centralización del americanismo - puede entenderse, en parte, que proyectos como los gestados en la $\mathrm{CdAB}$ y en la Universidad de 
Oviedo encontraran poco margen para su desarrollo autónomo. Hemos abordado con anterioridad otros aspectos de las confrontaciones suscitadas en este periodo $1909-1911,{ }^{5}$ en este trabajo y a la luz de documentación en su mayor parte inédita, ${ }^{6}$ nos centraremos en analizar, en un primer apartado, el devenir de la propuesta de carácter plural y de rango estatal bosquejada en Oviedo, basada en el intercambio de intelectuales. En un segundo apartado, analizaremos el fracaso de la propuesta federativa del americanismo barcelonés y su posterior retracción al ámbito económico y, en especial, al de la búsqueda de oportunidades para la inversión en el mercado americano. En un tercer y último apartado observaremos algunos de los dilemas y contradicciones a los que se enfrentaron los americanismos que denominamos periféricos, procurando comprender los aciertos y errores de la difícil gestión de los hombres del grupo de Oviedo y de la $\mathrm{CdAB}$, de cara al Estado, a la UIA y a los grupos americanistas de otras regiones del reino.

\section{El proyecto ovetense: estatizar y despolitizar al americanismo}

Entre 1898 y 1911, la Universidad asturiana, liderada por un dinámico núcleo de intelectuales krausoinstitucionistas conocido como "grupo de Oviedo", logró conformar un modelo de acción americanista que, teniendo una impronta regional y abrevando en sus propias tradiciones, hitos y fracasos, intentó definir y aspiró a orientar un programa integral de dimensión estatal para volver a vincularse con América, pero que resultó sustancialmente descentralizado. El paradigma, ya desarrollado en 1908, partió des-

5 Dalla Corte, Gabriela y Prado, Gustavo H.: "El movimiento americanista español en la coyuntura del Centenario. Del impulso ovetense a la disputa por la hegemonía entre Madrid y Cataluña”, Estudios Migratorios Latinoamericanos, revista del CEMLA, Buenos Aires, 19, 56, 2005, págs. 31-64; y "La Universidad de Oviedo y la Casa de América de Barcelona. La pluralidad del americanismo español en el contexto del Primer Centenario de las Independencias", Actas del Simposio Internacional De Ida y Vuelta. América y España: los caminos de la cultura, Santiago de Compostela, 2006, en prensa.

6 Las fuentes documentales corresponden a fondos que recogen los papeles y epistolario de tres personajes centrales en el movimiento americanista, como Rafael Vehils, director de la CdAB; Rafael Altamira, líder indiscutido del americanismo ovetense; y Rafael María de Labra, principal referente del movimiento a principios del siglo XX. Contrastamos aquí el intercambio epistolar entre estos personajes, conservado de manera fragmentaria en el Archivo de la Fundación Residencia de Estudiantes de Madrid/Fondo Altamira (AFREM/FA); en el Archivo Histórico de la Universidad de Oviedo, Fondo Rafael Altamira (AHUO/FRA); en el Instituto de Enseñanza Secundaria Jorge Juan de Alicante, Legado Altamira (IESJJA/LA); y en el fondo documental de la CdAB, resguardado en parte en la Biblioteca del Pavelló de la República de la Universitat de Barcelona y en la actual Casa América Catalunya. 
de el mero reclamo al Estado, ${ }^{7}$ pasó por el llamado de intelectuales americanos ${ }^{8}$ y emigrantes españoles voluntarios, ${ }^{9}$ y se coronó, en 1909-1910, con el exitoso "viaje americanista" protagonizado por su principal referente: el alicantino Rafael Altamira. ${ }^{10} \mathrm{El}$ americanismo ovetense ofreció a la sociedad española y al Estado una evaluación rigurosa sobre lo negativo que resultaba para el país que ambos mundos "hispanos" estuvieran separados. Se diseñó, entonces, una estrategia de intervención intelectual que definía a las universidades españolas como agentes privilegiados de la regeneración y de la reforma política, y las elevaba a la condición de foros alternativos de diálogo social e internacional, porque se las consideraba depositarias de una racionalidad superior, capaces de armonizar intereses regionales y estatales, así como valores supranacionales de tipo cultural, científico y humanista. Las casas de altos estudios podrían orientar y tutelar las líneas maestras de la política americanista, ofrecer apoyo técnico a la burocracia estatal y a las asociaciones privadas y administrar por sí mismas los aspectos culturales e intelectuales de las relaciones con América.

Pese a lo elaborado y "patriótico" del proyecto, al asombroso éxito de Altamira en América y a la extraordinaria repercusión que tuvo su retorno a España, el americanismo ovetense se toparía, casi de inmediato, con serios cuestionamientos ideológicos por parte de la propaganda católica asturiana ${ }^{11}$ y con la renuencia del Estado a convalidar su liderazgo en materia de política americanista. Así, en poco tiempo se vería que el resultado del magnífico triunfo de Altamira sería, sorprendentemente, la transforma-

7 Véase Altamira, Rafael: Discurso leído en la solemne apertura del curso académico de 1898 a 1899 por el Doctor D. Rafael Altamira y Crevea, catedrático numerario de Historia del Derecho, Establecimiento tipográfico de Adolfo Brid, Oviedo, 1898; Aramburu, Félix de, Canella, Fermín, Álvarez Buylla, Adolfo, García Alas, Leopoldo, Jove, Rogelio, Sela, Aniceto, Altamira, Rafael, Álvarez, Melquíades: "Al Congreso Hispano-Americano. Proposiciones que presentan al Congreso Hispano-Americano algunos catedráticos de la Universidad de Oviedo", Anales de la Universidad de Oviedo, I, Oviedo, 1901, págs. 389-390; y Altamira, Rafael: "Una ponencia. Medios creadores de una gran corriente de opinión que induzca a los Gobiernos de España, Portugal y pueblos iberoamericanos a realizar íntima alianza que permita resolver las cuestiones que puedan suscitarse entre las indicadas naciones por Tribunales arbitrales", España en América, F. Sempere y Compañía Editores, Valencia,1909, págs. 154-156.

8 Universidad de Oviedo: “A los centros docentes de América”, Anales de la Universidad de Oviedo, I, Oviedo, 1901, págs. 383-385.

9 Universidad de Oviedo: "A las colonias españolas de los Estados hispano-americanos", Anales de la Universidad de Oviedo, I, Oviedo, 1901, págs. 386-387.

10 Véase Prado, Gustavo H.: Rafael Altamira, el hispanoamericanismo liberal y la evolución de la historiografía argentina en el primer cuarto del siglo XX, Tesis Doctoral, Universidad de Oviedo, Oviedo, 2005 (disponible en formato CD editado en el año 2005).

11 Melón, Santiago: El Viaje a América del profesor Altamira, Universidad de Oviedo, 1987. 
ción del proyecto ovetense que lo había alentado. Es importante señalar que ciertos aspectos contradictorios y muy poco realistas de la estrategia ovetense no eran ajenos a esta transformación, que en parte puede ser vista como una derrota. En el proyecto la teoría sostenía sin problemas el ensamblaje de la autonomía universitaria con la supervisión de la burocracia ministerial y la satisfacción de los intereses del Estado. Aquel equilibrio no era viable no sólo porque suponía una redistribución efectiva de competencias centralizadas en beneficio de instituciones autónomas y un freno a la expansión estatal, sino también porque contemplaba, paralelamente, la necesidad de que el Estado se involucrara.

En efecto, el grupo de Oviedo consideraba imprescindible la participación estatal en cuatro registros: en la financiación de la reforma y expansión de las universidades españolas; en la coordinación de los recursos legales, comerciales, fiscales y burocráticos que jerarquizaran las relaciones con las antiguas colonias; en el subsidio de las actividades colaterales de la sociedad civil española residente y emigrante y, por último, en la legitimación ideológica necesaria para construir una comunidad panhispánica. La cuestión era, claro está, que la estrategia ovetense suponía simultáneamente la convocatoria y la contención del Estado, o lo que es lo mismo: proponía una fórmula que demandaba plena intervención absoluta a la hora de invertir recursos materiales y simbólicos mientras imponía su abstención casi completa en el diseño y gestión de la política americanista. Llámese a esto una integración auxiliar o subordinada del Estado, lo cierto es que Rafael Altamira, Fermín Canella y sus seguidores formulaban un esquema en el cual se procuraba la promoción del americanismo a la política de Estado, y lo preservaban al mismo tiempo del juego político partidista. Al sustraer la política americanista del influjo de la lucha facciosa y de los lentos circuitos de la burocracia, se esperaba poder instalarla en la esfera de instituciones relativamente autónomas como las universidades y entidades académicas.

El delicado equilibrio que demandaba la estrategia fue difícil de mantener por los mismos impulsores del plan ovetense: la necesidad de publicitar y atraer apoyos para el proyectado "viaje americanista" de Altamira, por un lado, y la urgencia por mantener el asunto dentro de los límites de la administración universitaria, por el otro, llevó al rector Fermín Canella a incurrir en ciertos errores y contramarchas que sólo lograrían atraer el interés de la clase política y la mirada atenta y alarmada de otros sectores que veían potencialmente amenazados sus propios proyectos como, por ejemplo, cuando el Rector ovetense filtró a la prensa progresista madrileña lo 
sustancial del proyecto, tras los fastos del Tercer Centenario de la Universidad de Oviedo.

Al tiempo que se cerraba el trato académico con la Universidad Nacional de La Plata para que Altamira dictara un curso sobre metodología de la historia en la Argentina, la Universidad de Oviedo era elogiada por el periódico madrileño El Imparcial por su proyecto de intercambio docente con las universidades americanas, estimando que era la vía adecuada para recuperar el prestigio internacional perdido. Las subsiguientes declaraciones de Canella contenían detalles acerca de la dificultades presupuestarias que suponía organizar un periplo de esta envergadura y la necesidad de contar con el apoyo gubernamental y periodístico para que así "España entera se interesase por lo que debe ser fecunda y trascendental misión". ${ }^{12}$ Fue precisamente esta invocación lo que llevó a la redacción de El Imparcial a reclamar que el gobierno y las cortes aportaran recursos a la iniciativa ovetense y a ofrecer aquella tribuna para que Segismundo Moret lanzara una suscripción pública para cubrir los costos del "viaje americanista" que debía emprender Altamira. ${ }^{13}$ Canella, sorprendido por la repercusión que habían tenido sus palabras y temeroso de que su proyecto adoptara una dimensión política - que aún el gobierno conservador no había aprobado—, rechazaría la suscripción. De esta manera, dejó en ridículo a El Imparcial y perjudicó, inmediatamente, las relaciones que mantenía con el periódico madrileño. ${ }^{14}$ Lo más sorprendente fue que, tras este rocambolesco episodio y gracias a los subsiguientes acontecimientos, el americanismo se convertiría en objeto del atento interés de conservadores, liberales y republicanos, cada vez más atraídos por su dinamismo.

Los triunfos de las etapas finales del viaje ovetense y el apoteósico retorno de Altamira a la Península causaron tal impacto en la prensa y en el ámbito gubernamental que el americanismo se transformaría, por un tiempo, en una cuestión de Estado. Pero en aquellas circunstancias tan promisorias como extraordinarias, no sería la Universidad de Oviedo, ni siquiera Rafael Altamira, quienes estarían mejor preparados para capitalizar sus propios éxitos. La dramática caída de Maura y el ascenso al poder

12 "El intercambio universitario", El Imparcial, Madrid, 14 de abril de 1909; véase también la carta de Fermín Canella a Luis López Ballesteros, Oviedo, 18 de abril de 1909, citada en Altamira, Rafael: Mi viaje a América (Libro de documentos), Librería de Victoriano Suárez, Madrid, 1911, págs. 28-29.

13 Carta de Segismundo Moret a Luis López Ballesteros, mayo de 1909, en Altamira, Mi viaje..., págs. 31-32.

14 AFREM/FA, carta de Fermín Canella a Rafael Altamira, Oviedo, 29 de enero de 1910. 
de los sectores más regeneracionistas del liberalismo abrieron nuevos canales de diálogo con la oposición socialista y republicana. La buena disposición del nuevo gobierno y su deseo de incorporar a los intelectuales reformistas en altos cargos de la burocracia ministerial y de ejecutar algunos de sus proyectos creó un nuevo clima que ni Canella ni Altamira - inmersos en la administración del periplo — pudieron percibir a tiempo, ni tampoco, para ser justos, se hallaban en condiciones de aprovecharlo.

Los interlocutores del gobierno liberal fueron, entonces, hombres muy próximos a Altamira que formaban parte de su mismo círculo ideológico y social e impulsaban un vasto programa de modernización cultural de inspiración krausoinstitucionista que los hombres del "grupo de Oviedo" y sus allegados suscribían plenamente. Los sectores más cercanos a la administración central en la compleja coyuntura de 1909-1910 recibirían de Canalejas y Romanones el encargo de construir un complejo institucional en torno a la Junta para la Ampliación de Estudios (JAE) bajo la órbita del Ministerio de Instrucción Pública, ${ }^{15}$ destinado a abrir el anquilosado mundo intelectual español al vivificador intercambio externo, incluyendo el intercambio universitario con América latina. ${ }^{16}$ De nada sirvieron los reclamos, las contrapropuestas ${ }^{17}$ ni las amargas quejas del rectorado ovetense o de Rafael Altamira ${ }^{18}$ : el Estado, tan reclamado por el movimiento america-

15 Véase el excelente trabajo de Naranjo Orovio, Consuelo; Luque, María Dolores y PuigSamper, Miguel Ángel (ed.): Los lazos de la cultura: el Centro de Estudios Históricos de Madrid y la Universidad de Puerto Rico, 1916-1939, Colección Tierra Nueva e Cielo Nuevo, CSIC-Universidad de Puerto Rico, Río Piedras, Madrid, 2002; también Niño Rodríguez, Antonio: "La II República y la expansión cultural en Hispanoamérica”, Hispania, Revista Española de Historia, 52, 181, 1992, págs. 629-653, donde el autor analiza la orientación de las relaciones con las antiguas colonias durante el periodo posterior, el de la Segunda República, fortaleciendo la comunidad de lengua, cultura e historia a través de un Plan de Actuación Cultural sostenido por el Ministerio de Estado.

16 Formentín Ibáñez, Justo, y Villegas Sanz, María José: Relaciones culturales entre España y América: la Junta para la Ampliación de Estudios (1907-1936), Mapfre, Madrid, 1992. La producción historiográfica, por su parte, siguió en importante derrotero en esos años como puede verse en el trabajo de Vélez Jiménez, Palmira: "Política e historiografía. El americanismo español hasta 1936", que será editado en Revista de Indias; agradecemos a la autora la cesión de este trabajo inédito.

17 Altamira, Rafael: "Medios prácticos para organizar las relaciones hispano-americanas (informe presentado y leído a Su Mejestad el Rey), Oviedo, 31 de mayo de 1910" y "Nuevas indicaciones sobre los medios prácticos para establecer y mantener las relaciones espirituales con los pueblos hispano-americanos”, ambos en Altamira, Mi viaje..., págs. 577-598 y págs. 639-642, respectivamente.

18 Testimonios de las comprensibles molestias que esto causó en Oviedo pueden encontrarse en Anales de la Universidad de Oviedo (1908-1910), Tipográfica de Flórez, Gusano y Cía., Oviedo, 1911, tomo V, págs. 536-537, así como en una serie de cartas privadas e inéditas conservadas en el AFREM/FA, que envió el Rector Fermín Canella a Rafael Altamira, fechadas el 14 de mayo, el 8 y el 14 de junio de 1910. 
nista, avanzaba ahora tardía pero implacablemente en el terreno cultural, y transfería a un organismo centralizado de su aparato burocrático el intercambio intelectual con América que Altamira soñaba con regularizar a través de las universidades. La mayoría de las diversas propuestas de Altamira y del claustro ovetense se estrelló en mediano o largo plazo, con la indiferencia del poder central; su implementación fue adjudicada, en el mejor de los casos, a otras instituciones como la JAE o el Museo Pedagógico, o fueron abiertamente resistidas y luego rechazadas por el gobierno ${ }^{19}$, como la creación de una Sección Americanista en la Universidad de Oviedo y un "Centro oficial de Relaciones hispano-americanas". ${ }^{20}$

Ahora bien ¿por qué la magnífica empresa americanista ovetense tuvo este desenlace? ¿Cómo pueden explicarse los desaires y la gran indiferencia mostrada a los reclamos del "grupo de Oviedo"? ¿Cómo entender que un proyecto patriótico, de cuya lealtad estatal nadie dudaba, fuera desarticulado de inmediato por el Estado, que se apropiaría de los réditos del capital americanista acumulado por Altamira o Canella para transferirlo a la burocracia ministerial? Para responder a estas preguntas debemos tener en cuenta el impacto decisivo de los dos aspectos clave de aquella coyuntura. En primer lugar, la politización inevitable del americanismo, abonada por la imprevisible repercusión americana del mensaje panhispanista ovetense y por el fenómeno de masas que suscitó el retorno de Altamira. En segundo lugar, el cambio paradójicamente favorable del clima ideológico que significaba el ascenso de políticos liberales, como Canalejas y Romanones, decididos a reformar el régimen restaurador, fortalecer el Estado y racionalizar su burocracia.

Sin embargo, cabe señalar que la derrota de la Universidad de Oviedo no debe explicarse con el auxilio de ninguna teoría conspirativa. Teniendo en cuenta el persuasivo discurso reformista y pedagógico de los intelectuales krausoinstitucionistas; convencidos de las bondades de la estrategia intelectual y elitista que proponían para restaurar las relaciones internacionales españolas en materia cultural, científica y económica y habiendo asumido buena parte de los argumentos y objetivos del programa americanista, los liberales verían en las ideas de estos hombres una serie de recetas que permitirían mejorar la gobernabilidad del sistema y jerarquizar la vilipendiada Restauración. Por eso tratarían de hacerlas propias y de cooptar a

19 Prado: Rafael Altamira, el hispanoamericanismo..., págs. 834-858.

20 IESJJA/LA, Altamira, Rafael: "Bases de organización del Centro de Estudios HispanoAmericanos", Madrid, 1911 (original mecanografiado). 
estos ideólogos para la política dinástica o, al menos, para altos puestos burocráticos, seduciéndolos con la promesa, más o menos explícita, de encargarles la ejecución de sus propios proyectos. Pero los tiempos políticos impusieron su ritmo y no esperaron por el viajero, compenetrado en sus labores en América, ni por Fermín Canella, sepultado entre los papeles de su despacho rectoral.

Desde esta perspectiva, puede comprenderse mejor tanto la "expropiación" de la que fue objeto la Universidad de Oviedo, como los límites de su estrategia de intervención americanista de signo estadista, descentralizador y "despolitizante". En este sentido, también es posible entender por qué la institución fue más perjudicada que el individuo. En efecto, Altamira tuvo interesantes compensaciones que debemos observar dentro de la lógica de cooptación que regía a la política dinástica y las propias concepciones reformistas del alicantino y su círculo. La ya conocida figura de Rafael Altamira había logrado tal relieve público que las jerarquías políticas liberales no dudaron en ofrecerle entre 1910 y 1913 una serie de atractivas compensaciones honoríficas, políticas y laborales por sus servicios al país. ${ }^{21}$ Con todo, el orgullo intelectual de Altamira le impediría estar personalmente satisfecho. El proyecto americanista del grupo de Oviedo, que le era en gran medida propio y preveía una gestión autónoma del intercambio intelectual por parte de las universidades españolas, fue asumido por el gobierno central que derivaría tales menesteres en instituciones guiadas por otras lógicas y finalidades, las cuales terminarían por desatender el programa americanista.

\section{De la regionalización a la federación del americanismo: la estrategia catalana}

El americanismo barcelonés, impulsado por el mundo de los grandes negocios catalanes definió, por su parte y a través de la asociación privada $\mathrm{CdAB}$, una estrategia de intervención prioritariamente comercial e inversora que supo abrir una brecha en el esquema centralizador de la unidad ame-

21 A la Cruz de Alfonso XII y al nombramiento de Inspector y luego Director General de Primera Enseñanza, se sumaron su integración en la estructura de la propia JAE como director de sección del Centro de Estudios Históricos; su nombramiento como numerario de la Real Academia de Ciencias Morales y Políticas y la creación de una cátedra de americanista en la Universidad Central de Madrid. 
ricanista avalada por otros grupos del reino, en particular el concentrado en torno a la UIA, como veremos aquí. Emprender la aventura americana y conformar un americanismo plural que integrara a los hispanos residentes en el "nuevo" continente fueron dos de los desafíos — si no los más importantes - que planteó la progresiva consolidación del americanismo catalán. ${ }^{22}$ En este modelo, los agentes privilegiados de la acción americanista eran, sin lugar a duda, las asociaciones regionales sostenidas por intereses locales y eventualmente asistidas por el Estado. Además de vivificar el abstracto ideal americanista y encarnarlo en la realidad de la sociedad civil, estas asociaciones deberían fortalecerse a través de la colaboración con sus homólogas españolas y proponer soluciones federativas que armonizaran los intereses divergentes y definieran una unidad de acción razonable de cara a Latinoamérica y al propio Estado. Tal estrategia permitiría obtener mayores réditos ante la dinámica y eficaz competencia de Francia, Gran Bretaña, Alemania e Italia y ante los avances experimentados por los Estados Unidos, país que ya se había dotado en 1910 de un poderoso instrumento de acción americanista como la Unión Panamericana de Washington, creada sobre la precedente Oficina Internacional de las Repúblicas Americanas. Apenas concluido el famoso Congreso Hispanoamericano de 1900, el proyecto inspiró el lanzamiento un año después de la Revista Comercial Iberoamericana Mercurio, que impulsó en 1903 la misión comercial a la Argentina de Federico Rahola y Tremols y del republicano Jusé Zuleta, misión de exploración que recibiría el espaldarazo monárquico; la fundación de la Sociedad Libre de Estudios Americanistas en 1909, y del Club Americano en 1910; así como la coronación del movimiento con la fusión de ambos organismos en la Casa de América de Barcelona en abril de 1911. Hasta entonces las actividades desarrolladas por el grupo catalán - liderado por personajes claves de la Lliga Regionalista tales como Verdaguer i Callís, Francesc Cambó, Rafael Vehils, ${ }^{23}$ o por el empresariado importador-exportador concentrado en el

22 Véase dos trabajos realizados a partir de la documentación del fondo Josep Maria Figueras, Pavelló de la República de la Universitat de Barcelona, que conserva parte del archivo de la CdAB: la tesis de licenciatura inédita de Yáñez Gallardo, César: El americanismo de la burguesía catalana, 1898-1929: un proyecto imperialista, UAB, Bellaterra, mimeo; y Dalla Corte, Gabriela: Casa de América de Barcelona (1911-1947), Comillas, Cambó, Gili, Torres y mil empresarios en una agencia de información e influencia internacional, Editorial LID, Madrid, 2005.

23 Vehils sería la mano ejecutora de los proyectos ideados por Francesc Cambó hasta la muerte de este último en la Argentina en 1947; sobre Vehils véase Quijada, Mónica: Aires de República, Aires de Cruzada: la Guerra Civil Española en Argentina, Sendai, Barcelona, 1991. 
Fomento del Trabajo Nacional y en la Compañía Trasatlántica ${ }^{24}$ - no habían despertado recelos en grupos similares del reino o en el gobierno central. Pero a partir del año 1911, y en los momentos claves de la historia europea (como la creación de la Compañía Hispanoamericana de Electricidad, más conocida como CHADE, que pasaría a sostener económicamente a la entidad americanista catalana ${ }^{25}$ ), se verifica una abierta oposición a la autonomía de las propuestas barcelonesas, lo que llevó a sus protectores a preferir un ámbito más económico que cultural, a diferencia del que proponía Altamira desde Oviedo. En ese sentido, en la CdAB acabaría primando el ideal de los "indianos" del Club Americano, frente al que impulsó a reunirse en el contexto del Centenario de las Independencias a los intelectuales de la Sociedad Libre de Estudios Americanistas.

El americanismo catalán apostaba al desarrollo autónomo de sus instituciones y proyectos, sin dejar de reclamar - al igual que haría el americanismo ovetense - el apoyo presupuestario y la legitimación estatal, amparándose en su plena identificación con un proyecto regenerador y eminentemente "patriótico" como el americanista. El plan que intentaba atraer tanto a los políticos y hombres de negocios catalanistas, como seducir a la corona, a los líderes de los partidos dinásticos y a los principales referentes del americanismo español, no obtuvo grandes resultados. Cuando la CdAB lanzó su audaz y controvertida propuesta de convocar una asamblea de asociaciones americanistas en Barcelona, para constituir una federación que coordinara sus esfuerzos en toda España, se pudieron percibir por primera vez las oposiciones y resistencias que inspiraba la acción catalana a la vez que ésta pretendía avanzar sobre terrenos en los que, por diversas razones, el Estado u otras asociaciones americanistas reclamaban primacía. Particularmente importante para el americanismo catalán resultó el rápido entendimiento que lograron Labra y el director de la CdAB, Rafael Vehils. Si este diálogo fue posible y resultó fructífero, fue porque existía un diagnóstico común: tanto para el hispanocubano como para el

24 Rodrigo Alharilla, Martín: Los Marqueses de Comillas 1817-1925, Antonio y Claudio López, LID Editorial, Madrid, 2000; también la versión Antonio López y López (1817-1883) primer Marqués de Comillas un empresario y sus empresas, Fundación Empresa Pública, Madrid, 1996.

25 Dalla Corte, Gabriela: "Empresas, asociaciones y redes sociales en el Cono Sur: el sector de la electricidad (1920-1940), en Mameli, Laura y Muntañola, Eleonora (eds.): América Latina, Realidades diversas, Aula Oberta 2001-2005, UAB-Casa Amèrica Catalunya, 2005, págs. 465-488; Riquer i Permanyer, Borja: El último Cambó (1936-1947). La tentación autoritaria, Grijalbo, Barcelona, 1997; también Ucelay da Cal, Enric: El Imperialismo catalán: Prat de la Riba, Cambó, D'Ors y la conquista moral de España, Edhasa, Barcelona, 2003. 
catalán —que en ocasiones gustaba presentarse como uruguayo o puertorriqueño - gran parte de los males y divisiones que comenzaban a aquejar al americanismo español eran fruto de la pretensión de exclusividad de las asociaciones madrileñas, sobre todo de la UIA. De ahí que para Labra fuera necesario emprender una labor tendiente a "armonizarlas o, por lo menos relacionarlas un poco" para así poder aprovechar la oportunidad que representaba la efemérides del primer centenario de las independencias. ${ }^{26}$

Durante aquellos meses, Labra comprometió el apoyo de las Sociedades Económicas del norte de la Península y se mostró optimista respecto de la posibilidad de incorporar una "voz de tierra adentro" que fortaleciera el proyecto federativo, sumando, por ejemplo, a las Sociedades Económicas castellanas y riojanas, así como a las instituciones americanistas andaluzas. Pese a las reservas que confesara Labra a Altamira acerca de la viabilidad política del proyecto federativo, el primero apoyó activamente la iniciativa catalana convencido de que ella representaba la glosa de su "pequeño programa sobre el problema hispano-americano" que, no había despertado entusiasmo alguno en Madrid. ${ }^{27}$ Claro que Labra no dejaba de apreciar que la UIA pondría serios obstáculos a los proyectos de Vehils y Rahola, los cuales se potenciarían con los recelos - en gran medida, injustos- que estaban despertando las circulares de la $\mathrm{CdAB}$ en los demás centros americanistas españoles; ${ }^{28}$ por lo tanto, no debe perderse de vista que la voluntariosa y enérgica gestión que hizo Vehils del proyecto federativo no ayudaría a revertirlos. Persuadido de estar en posesión de una fórmula acabada para organizar al americanismo, reluctante a cualquier negociación que pudiera alterar el calendario o el orden del día propuesto, Vehils no invirtió demasiado esfuerzo en trabar compromisos personales con los dirigentes de las asociaciones convocadas, y delegó en Labra la actividad propagandística.

Lo cierto es que la gestión de Vehils estuvo basada en el supuesto de que las entidades convocadas sólo podían decidir si aceptaban o no la propuesta cerrada que les acercaba Barcelona. Así pues, una vez lanzada la convocatoria, cuando comenzaron a divulgarse los inevitables inconvenientes de agenda, equívocos y ocurrencias que amenazaban con alterar aquella rígida hoja de ruta, se manifestaron los límites del talante negociador de

26 CdAB, carta de Rafael M. de Labra a Rafael Vehils, 19 de junio de 1910.

27 IESJJA/LA, carta de Rafael M. de Labra a Rafael Altamira, Madrid, s/f.

28 CdAB, carta de Rafael M. de Labra a Rafael Vehils, 9 de septiembre de 1911, 19 de septiembre de 1911; s/f (octubre o noviembre) 1911; 16 de noviembre de 1911. 
la $\mathrm{CdAB}$. En efecto, el exceso de celo de Vehils provocó un conflicto por la fecha y sede de celebración de la futura asamblea con la Sociedad Columbina Onubense (SCO). Vehils consideró la mala interpretación de las convocatorias catalanas por el referente americanista de Huelva, Marchena Colombo, una conspiración para arrebatar a Barcelona el control mismo de su proyecto y la hegemonía sobre la futura federación. Labra se encargó de recomponer las relaciones entre la $\mathrm{CdAB}$ y la $\mathrm{SCO}$ y de negociar una nueva fecha significativa, aunque menos problemática que la original del 12 de octubre, para celebrar la asamblea en Barcelona. Así, para inicios del mes de octubre, el grupo barcelonés ya había aceptado la sugerencia de Labra de convocar el encuentro para el 4 de diciembre de 1911, haciéndolo coincidir con el XXV aniversario de la votación por la que las cortes españolas habían "reconocido" las independencias americanas. Más tarde, y debido a problemas de agenda de Labra, la CdAB aceptó una nueva postergación, y pospuso la sesión inaugural hasta el 14 y 16 de diciembre. ${ }^{29}$

Consciente de la ansiedad que reinaba en la $\mathrm{CdAB}$ y de las diferentes sensibilidades existentes en el movimiento, en reiteradas ocasiones, Labra le advirtió a Vehils de la necesidad de obrar con "calma y arte" para evitar rozamientos y rivalidades que pudieran comprometer la unidad plural e independiente del americanismo español. ${ }^{30}$ Además de pedir sosiego, recomendó a Vehils que tomara nota de la realidad regional de España, con la que el americanismo tenía que operar si quería construir una auténtica Federación Nacional:

"Hay que proceder con cautela y que sortear el peligro de que los émulos den al noble y práctico pensamiento de Vds. el aire de una obra exclusivamente catalana. Ya hablaremos de eso... aquí ha estado el Sr. Berenguer de Valencia y hemos hablado largamente de V. y de la organización de los americanistas valencianos". ${ }^{31}$

Si bien los americanistas catalanes aceptaron los consejos puntuales de Labra, no parecen haber sido capaces de comprender el sentido profundo de sus advertencias, cuando hizo notar que las gestiones de Labra no harían rectificar el rechazo de la UIA y de su líder, el conservador asturia-

29 CdAB, carta de Rafael Vehils a Rafael M. de Labra, 21 de septiembre de 1911; carta de Rafael M. de Labra a Rafael Vehils, 14 de julio de 1911, 9 de septiembre de 1911; 19 de septiembre de 1911; 7 de octubre de 1911.

30 CdAB, carta de Rafael M. de Labra a Rafael Vehils, 9 de septiembre de 1911 y 19 de septiembre de 1911.

31 CdAB, carta de Rafael M. de Labra a Rafael Vehils, 16 de julio de 1911; s/f, octubre o noviembre de 1911. 
no Faustino Rodríguez de San Pedro, Vehils jugó su segunda baza: Rafael Altamira. El interés por captar al alicantino, director general de Primera Enseñanza, se relacionaba también con su posibilidad de acceder al liberal Amalio Gimeno, por entonces ministro de Instrucción Pública. Para decepción de la $\mathrm{CdAB}$, y pese a su compromiso inicial, Altamira mantuvo cierta distancia respecto de la iniciativa catalana, la cual pareció ampliarse debido a la evolución del conflicto con la UIA. A tal punto llegarían las cosas que, para el mes de septiembre de 1911, era notorio que Vehils temía una eventual defección de Altamira que arrastrara tras de sí al Gobierno y al resto del americanismo español. ${ }^{32}$

En aquellos días, Vehils remitiría a Altamira varias cartas y cuidadas copias de la correspondencia cruzada con la UIA, para que el alicantino pudiera observar la magnitud del recelo que despertaba la iniciativa en la asociación y para indicarle lo imperioso de su presencia y la del ministro Gimeno en la asamblea convocada para diciembre de $1911 .{ }^{33}$ Pese a la significativa ausencia de la UIA y a la frialdad de varias de las asociaciones asistentes, el encuentro se celebró finalmente con un programa elaborado según los términos y deseos de Rafael Vehils y de Federico Rahola. Se resolvió constituir una comisión ejecutiva y una comisión nacional — ambas lideradas por Labra—, encargadas de concretar los acuerdos y de organizar la federación de asociaciones americanistas españolas. Sin embargo, una vez que se disipó el entusiasmo fundacional, poco pudo hacerse: las comisiones, reunidas irregularmente en la casa de Labra, no lograron sobrevivir demasiado tiempo y el proyecto de la federación terminó cayendo por el peso de sus poderosos objetores y, en gran medida, por la incapacidad de la $\mathrm{CdAB}$ para inspirar confianza sobre la transparencia de sus propósitos e intereses entre los referentes americanistas y los altos cargos del gobierno.

Ahora bien ¿por qué fracasó el primigenio proyecto federativo impulsado por los americanistas catalanes? ¿Por qué fue viable la rápida conformación del complejo institucional americanista en torno del Mercurio o la fundación de una institución tan ambiciosa y polifacética como la $\mathrm{CdAB}$, frustrándose el paso siguiente que era la federación? ¿Por qué el Estado

32 AHUO/FRA, carta de Rafael Vehils a Rafael Altamira, Barcelona, 9 de septiembre de 1911.

33 AHUO/FRA, carta de Rafael Vehils a Rafael Altamira, Barcelona, 25 de noviembre de 1911; carta de Rafael Vehils y Federico Rahola a Amalio Gimeno, 13 de noviembre de 1911 (copia); carta de Rafael Vehils a Rafael Altamira, Barcelona, 4 de noviembre de 1911 y 15 de noviembre de 1911 . 
legitimó y hasta apoyó proyectos sucesivos de la CDAN, pero no intervino apuntalando la unidad de las asociaciones americanistas del reino, planteada a finales de 1911? Para responder estos interrogantes debemos revisar no sólo la estricta coyuntura, sino también los aspectos centrales de la estrategia catalana (comparándola con la seguida por los miembros del grupo de Oviedo) la cual pretendía fortalecer la autonomía de los intereses catalanes, sin dejar de invocar las presuntas corresponsabilidades del Estado en el sostén material de sus proyectos. La explicación fundamental, no obstante, hay que buscarla en el proyecto de la $\mathrm{CdAB}$ de convertirse en una entidad articuladora entre América Latina y Europa. En parte, el avance de la $\mathrm{CdAB}$ en terrenos políticos, diplomáticos e ideológicos que eran considerados propios del Estado fue interpretado como una transgresión al esquema que, de manera tácita, había permitido la convivencia entre los diversos grupos que emergieron en la primera década del siglo XX. La ansiedad de Vehils, además, puede explicar la desconfianza de Huelva y Bilbao así como la frialdad con que Oviedo y los americanistas gallegos recibieron la iniciativa de la $\mathrm{CdAB}$. En todo caso, es evidente que aquellos reparos del resto del americanismo peninsular respecto del proyecto federativo marcaron el destino de la $\mathrm{Cd} \mathrm{AB}$ que se hizo más proclive a abrir sus proyectos a los latinoamericanos establecidos en Cataluña y a los españoles radicados en América. El fracaso federativo jugó su papel en el repliegue económico del americanismo catalán, pero también intervinieron otros factores no menos importantes. En efecto, no sólo existían los límites estructurales del diseño catalán frente a los intereses gubernamentales, sino también frente a los otros grupos americanistas del reino; en particular en la relación con la SCO, asociación que, respaldada por Labra, terminó por lanzar su propio proyecto federal para fastidio de Vehils que veía así enterrada cualquier esperanza de resucitar la federación por él propuesta. ${ }^{34}$

La federación podía construir en Barcelona un polo americanista alternativo a la hegemonía madrileña, aunque refrendada por el Estado. Un polo en el que predominaban sociedades del ámbito cultural e intelectual, en el que los intereses económicos catalanes no serían contrastados por las Sociedades Económicas de Amigos del País, y desde el cual se podría negociar en términos favorables con las Cámaras comerciales regionales que se interesaran por el mercado americano. Esta gestión funcionaría con bastante éxito siempre y cuando no se sobrepasara el ámbito económico ni se reba-

34 CdAB, carta de Rafael M. de Labra a Rafael Vehils, 30 de junio de 1912 y de Rafael Vehils a Rafael M. de Labra, 8 de julio de 1912. 
sara el radio regional. No debería sorprendernos el hecho de que la unidad plural del americanismo predicada desde Cataluña tuviera un límite en la cobertura de sus intereses prioritariamente económicos. La médula económica del proyecto acercó a la entidad a los extranjeros y a los residentes peninsulares en el exterior con los que se quería hacer negocios y establecer mayor intimidad. Quizás por ello, varios años después de fracasada la iniciativa catalana, Vehils aconsejó a los miembros de la CdAB desligarse de los americanistas de La Coruña y del cónsul chileno Ernesto Cadiz, que planeaban fundar en Galicia una Casa de América. ${ }^{35}$ La propuesta barcelonesa de federar el americanismo en el ámbito de la sociedad civil, y la idea de enlazarlo con entidades surgidas al calor de la emigración española e incluso con intereses estrictamente latinoamericanos representó un salto cualitativo en el diseño catalán, pero coincidió con el ingreso del americanismo en un lugar importante en la agenda del poder y forzó a adoptar una dirección distinta a partir del año 1912. En ese año, los hombres de la CdAB, al tiempo que luchaban para que la federación no se extinguiera y publicitaban en Madrid y con el apoyo de Labra su visión del americanismo, ${ }^{36}$ lanzaron otro ambicioso proyecto que terminó por absorber sus esfuerzos. El 10 de mayo de 1912 Vehils dio cuenta a la CdAB de los resultados de la comisión enviada a Zaragoza y a Madrid para planear la constitución de una federación de españoles residentes en América que debía tomar cuerpo a través de la propia CdAB. Para obtener el apoyo de los emigrantes radicados en el nuevo continente, Vehils se propuso encabezar una nueva misión a la América del Sur que recibiría el carácter de "oficial" por parte del gobierno, respaldado en esta oportunidad por el Ministerio de Fomento y de Estado. ${ }^{37}$ La nueva

$35 \mathrm{CdAB}$, Registro de acuerdos del Consejo de gobierno, 29 de abril de 1920. Cabe señalar que estos proyectos se mantuvieron y, en algunos casos, cambiaron, durante la República, hasta la crisis de la Guerra Civil. Véase el trabajo colectivo de Pérez Herrero, Pedro y Tabanera, Nuria (coord.): España/América Latina: Un siglo de políticas culturales, AIETI/Síntesis-OEI, Madrid, 1992; Tabanera, Nuria, Ilusiones y desencuentros: la acción diplomática republicana en Hispanoamérica (1931-1939), CEDEAL, Madrid, 1996; también Bernabéu Albert, Salvador: "El americanismo en el Centro de Estudios Históricos: Américo Castro y la creación de la Revista Tierra Firme (1935-1937)", ponencia presentada al Segundo Congreso Internacional de Instituciones Americanistas "Fondos documentales desde las independencias al bicentenario", realizado en Barcelona por la Casa Amèrica Catalunya, octubre de 2005; y su trabajo previo: "Un señor que llegó del Brasil": Americo Castro y la realidad histórica de América”, Revista de Indias, 62, 226, 2002, págs. 651-674.

$36 \mathrm{CdAB}$, carta de Rafael Vehils a Rafael M. de Labra, 27 de febrero de 1912; carta del presidente de la CdAB a Rafael M. de Labra, 26 de febrero de 1912; carta de Rafael Vehils a Rafael M. de Labra, 9 de marzo de 1912; carta de Rafael M. de Labra a Rafael Vehils, 30 de junio de 1912.

37 CdAB, Registro de acuerdos del Consejo de gobierno, 10 y 20 de mayo de 1912; 30 de junio de 1912 . 
"misión", que llevaría a Vehils a Sudamérica antes de que se cumpliera una década del viaje inaugural de Rahola y Zulueta, ${ }^{38}$ no reprodujo literalmente el espíritu comercial que había guiado a estos últimos en 1903. En realidad, detrás de la fachada fraternal de la misión comercial se contemplaba la idea de recaudar subvenciones para la futura federación entre de asociaciones españolas en América. ${ }^{39}$

La consecuencia más importante de la misión de Vehils a Uruguay, Paraguay y la Argentina fue la conversión de la $\mathrm{CdAB}$ en una entidad de competencia internacional. Mediando la modificación estatutaria, la asociación privada americanista barcelonesa se convirtió desde entonces en una "oficina internacional económica, subvencionada por los gobiernos español y americanos". ${ }^{40}$ Después de un año de reveses, podemos suponer que Vehils se sorprendió ante la aceptación externa de que gozaba su nuevo emprendimiento: la $\mathrm{CdAB}$ reencontraba así su camino y esta situación animaría a su eterno director a solicitar a Alfonso XIII que se sumase a la asociación catalana como presidente honorario. Una vez más, el recurso a los referentes americanistas o a miembros claves del panorama político español parecía rendir frutos. ${ }^{41}$ En este contexto favorable se consiguió el auspicio del monarca para la celebración en Barcelona de una conferencia internacional iberoamericana de cámaras españolas de comercio, ${ }^{42}$ proyecto que tendría que esperar al año 1923 para concretarse, resuelto ya el terrible bache de la Primera Guerra Mundial, consolidada la CHADE como la socia más importante de la $\mathrm{CdAB}$ con una cuota anual de más de 12.000 pesetas, y habiéndose incorporado Francesc Cambó — líder de la Lliga Regionalista, mecenas de la CdAB, y vicepresidente de la empresa de electricidad - al sistema gubernamental como Ministro de Fomento primero y de Hacienda después. ${ }^{43}$

38 CdAB, carta de Rafael Vehils a Rafael M. de Labra, 8 de julio de 1912.

39 En 1913 el gobierno argentino le concedió una subvención de 2000 pesos oro, es decir, aproximadamente 10.800 pesetas que equivalía a la cuota anual que pagaba la Compañía Trasatlántica a la $\mathrm{CdAB}$ para formar parte de su grupo empresarial más importante.

$40 \mathrm{CdAB}$, Registro de acuerdos del Consejo de gobierno, 14 de febrero de 1914; 25 de abril de 1913, 10 de junio de 1913.

41 CdAB, carta de Rafael Vehils a Rafael M. de Labra y Martínez, 22 de enero de 1912, 27 de enero de 1912 y 23 de septiembre de 1912; AHUO/FRA, carta del presidente de la CdAB a Rafael Altamira, Barcelona, 29 de septiembre de 1912.

$42 \mathrm{CdAB}$, Registro de acuerdos del Consejo de gobierno, 20 de setiembre de 1912.

43 Véase los importantes trabajos de Ucelay-Da Cal, Enric: "La dimensión desconocida: Cambó en Buenos Aires, entre Franco y Perón, 1941-1946”, Revista Historia Social, 48, 2004, págs. 87-109, y de Riquer i Permanyer, Borja: "Un milionari a l’americana. Estratègia patrimonial i inversora de Francesc Cambó”, Josep Fontana, Història i Projecte social, Reconeixement a una trajectòria, Crítica, Barcelona, 2004, págs. 1233-1248. 


\section{Pluralismo y soporte estatal: dilemas y contradicciones del americanismo periférico}

Fruto del contexto ideológico finisecular y de una determinada forma de pensar la sociedad civil y el papel del Estado, uno de los grandes problemas del americanismo catalán y ovetense radicaba en resolver los dos dilemas encadenados que les planteaban sus ambiciosas aspiraciones que lo impulsaban, por un lado, a proyectar su propuesta allende su terruño, procurando atraer el interés de americanistas de otras regiones pero pretendiendo mantener la identidad de su iniciativa; y, por otro lado, a convocar la asistencia material y el apoyo político del Estado, pretendiendo mantener su autonomía y el control de sus gestiones y proyectos.

Pese a lo arriesgado de este recurso al auxilio estatal que elevaron prematuramente tanto el americanismo ovetense como el catalán, lo cierto es que en la política interna del americanismo español existía este tipo de tensiones que terminaría por anular sus respectivas líneas de fuerza en un juego en el que sólo prevalecerían proyectos apoyados decididamente por la fuerza estatal. Las tensiones no eran muy diferentes de aquellas que afectaban a todos y cada uno de los aspectos de la política española de la época. Las desconfianzas que interfirieron en el desarrollo cooperativo del americanismo español no deben ser vistas como el resultado del "faccionalismo", sino como la expresión de un insoslayable conflicto de intereses y visiones del asunto que enfrentaban a los diferentes impulsores de este movimiento. De este modo, conflictos que oponían a los proyectos tenían un fundamento ideológico y territorial, pero también es imposible no ver en ellos la impronta, supuestos y limitaciones de aquellas fracciones de la burguesía española que diseñaron o avalaron, respectivamente, aquellas propuestas: la elite intelectual reformista, krausoinstitucionista y regeneracionista; los núcleos más dinámicos del comercio y finanzas orientados al mercado internacional y la elite política liberal-conservadora que dominaba el aparato estatal y garantizaba la estabilidad del sistema oligárquico de la Restauración.

En efecto, la estrategia intelectual ovetense consideraba las instituciones estatales relativamente autónomas del influjo político y legitimadas por su campo específico de acción científica, centrado en las universidades, ámbitos ideales para el diseño y orientación de la política americanista racional. Desde esta perspectiva se desconfiaba del pragmatismo de la 
burocracia gubernamental -en un Estado estructurado por el caciquismo al que denunciaban por su venalidad-, como del asociacionismo regional que amparaba intereses económicos. El americanismo catalán representado por la $\mathrm{CdAB}$, por su parte, impulsaba una fórmula de institucionalización no gubernamental que propugnaba la colaboración de todas las asociaciones americanistas, preservando los intereses españoles comunes a través de una fórmula federal que unificara la acción americanista sin cuestionar su pluralidad y heterogeneidad constitutiva y que lograra negociar con el Estado un equilibrio aceptable para los intereses regionales. Este americanismo, naturalmente antagónico con el de otros grupos, como el representado por la UIA, también era reacio a confiar plenamente la dirección de la política americanista a unos intelectuales asentados en instituciones universitarias solventadas por el Estado que, por lo demás, estaban lejos de haber asumido en conjunto los planteamientos del reformismo liberal y mucho más todavía de comprender las propuestas catalanas de la Lliga Regionalista de la que provenía la mayor parte de los miembros de la $\mathrm{CdAB}$, en particular su director, Rafael Vehils.

Frente a las alternativas que planteaban los americanistas de Barcelona y Oviedo, el Estado se mostraría propenso a apoyarse en la autoridad de la UIA y a favorecer, de manera tendenciosa, la centralización del movimiento que combinaba, en primer lugar, la cooptación de los intelectuales; en segundo lugar, la acotación de la acción americanista autónoma de algunos ámbitos universitarios que eran considerados molestos reductos de la oposición republicana y de la reacción confesional; y, en tercer lugar, el arrinconamiento sectorial de las instituciones existentes, procurando disuadirlas de cualquier pretensión de controlar la política americanista, capítulo de la política exterior y, por ende, potestad inalienable del Estado. Si la rivalidad latente entre modelos que propugnaban un desarrollo plural del americanismo — sin impugnar necesariamente su unidad - y aquel que se hacía fuerte en un proyecto unitario que centralizara los esfuerzos y garantizara la coherencia de una política de Estado que involucraba complejos aspectos diplomáticos, económicos, simbólicos, culturales e intelectuales debía derivar en inevitables fricciones y pujas, ello no fue óbice para que se manifestara otro tipo de rivalidades entre quienes compartían, en principio, más coincidencias que discrepancias. Los múltiples puntos de intersección que existían entre las iniciativas que avalaban la pluralidad, como la catalana y la asturiana, pero también las de menor rango y ambiciones como la gallega o la valenciana, no alcanzaron para coordinarse sin 
que afloraran posturas renuentes en el americanismo andaluz, mallorquín y vasco. Así pues, por encima de las coincidencias y colaboraciones, también Oviedo y Barcelona rivalizaron no sólo por el talante y orientación de sus proyectos, sino también porque ambas aspiraban a reclutar el apoyo de las reacias instituciones estatales y atraer inversiones del erario público.

Las pretensiones hegemónicas y los importantes logros de asturianos y catalanes resultaron paradójicamente contraproducentes para cohesionar las expresiones periféricas del americanismo. Tanto la lealtad estatal de ambas iniciativas, como el supuesto ampliamente extendido entre la elite liberal-reformista de que el concurso del Estado era imprescindible para el éxito de cualquier proyecto asociativo crearon las condiciones para que muchos de sus referentes convalidaran, en última instancia, el avance estatal para absorber al movimiento americanista y evitar su disgregación. Más allá de la contraposición de intereses, ideas y personalidades, estos condicionantes ideológicos también contribuyeron a reorientar entre 1910 y 1911 los proyectos alternativos que aquí analizamos. En efecto, si bien la solidez del diseño ovetense no debe ponerse en duda, su realización demandaba una madurez institucional que no existía en la coyuntura finisecular española. En este marco, convocar el auxilio del Estado pretendiendo convencer a sus administradores de abstenerse de controlar políticamente los réditos del proyecto americanista resultaba aventurado. Sin embargo, los intelectuales ovetenses, inmersos en el horizonte social e ideológico del liberalismo-reformista, no pudieron sustraerse de tomar el desafío pedagógico de persuadir a la clase política de la racionalidad evidente de su propuesta, desatendiendo otras estrategias que, tal vez, podrían haber resultado más eficaces. La apuesta por el Estado eclipsó una vía más plausible para consolidar el americanismo coordinando esfuerzos con otras universidades e instituciones académicas españolas para construir, desde los márgenes, una alternativa a la centralización política y burocratización ministerial. En el caso catalán, las necesidades políticas hicieron que los hombres del Mercurio y de la CdAB se ocuparan en demasía de promover el favor gubernamental y de reclamar a un Estado centralizado y en proceso de consolidación, actitudes "federales" respecto de los intereses regionales. Así, por estas razones, por los intereses comerciales inmediatos que sostenían a la $\mathrm{CdAB}$ y por la necesidad de legitimarse, los americanistas catalanes prefirieron acercarse a los círculos políticos nacionales y a los ámbitos universitarios, académicos y culturales, antes que favorecer la multiplicación de otras Casas de América que habrían podido competir con 
ella, pero que al mismo tiempo le habrían permitido conformar un polo de poder más consistente desde donde defender sus intereses.

Las ambiciones totalizadoras que manifestaron tanto el americanismo catalán como el asturiano alarmaron al Estado y expandieron su competencia a campos que no controlaban pero pretendían dominar de manera hegemónica. La interacción de estos factores estructurales y coyunturales coadyuvó a que el movimiento americanista se debilitara tras su momento de máxima fortaleza - tras el retorno de Rafael Altamira de su expedición continental y al proyectarse la fundación de la $\mathrm{CdAB}$ - , y agotara el prestigio que con tanto trabajo había ganado y sus limitadas energías en una vigorosa invocación de la asistencia estatal. La coyuntura de 1910-1912 dispersó en parte el americanismo ovetense, acotó el movimiento catalán y fue el preludio del avance estatal sobre este movimiento en los años de la dictadura de Primo de Rivera y, luego, durante el régimen franquista, bajo la inspiración de una concepción alejada de los presupuestos liberales, reformistas y progresistas que habían orientado al americanismo español entre 1898 y $1923 .{ }^{44}$ 